\title{
Stromal expression of Fer suppresses tumor progression in renal cell carcinoma and is a predictor of survival
}

\author{
KENSUKE MITSUNARI, YASUYOSHI MIYATA, SHIN-ICHI WATANABE, \\ AKIHIRO ASAI, TAKUJI YASUDA, SHIGERU KANDA and HIDEKI SAKAI
}

\author{
Department of Urology, Nagasaki University Graduate School of Biomedical Sciences, Nagasaki 852-8501, Japan
}

Received June 28, 2015; Accepted October 21, 2016

DOI: $10.3892 / \mathrm{ol} .2016 .5481$

\begin{abstract}
Fps/Fes related (Fer) is a non-receptor tyrosine kinase that is expressed in fibroblasts, immune cells and endothelial cells. Fer serves an important pathological role in cell survival, angiogenesis and the immune system. However, the pathological role of Fer expression in the stromal cells surrounding renal cell carcinoma (RCC) has not been previously investigated. In the present study, immunohistochemical analysis of Fer was performed using the formalin-fixed tissue samples of 152 patients with RCC. The proliferative and apoptotic indices were used to represent the percentage of proliferation marker protein Ki-67- and cleaved caspase-3-positive cells, respectively. The microvessel density was defined as the number of cluster of differentiation (CD) 31-positively stained vessels $/ \mathrm{mm}^{2}$. In addition, $\mathrm{CD} 57^{+}$and $\mathrm{CD} 68^{+}$cells were counted using semi-quantification of natural killer (NK) cells and macrophages. Fer expression in stromal cells was negatively associated with Fuhrman grade, pathological tumor stage and metastasis $(\mathrm{P}<0.001)$. Fer expression in stromal cells was negatively associated with $\mathrm{CD} 68^{+}$macrophage density, whereas it was positively associated with $\mathrm{CD} 57^{+}$ NK cell density. Kaplan-Meier estimators indicated that decreased stromal Fer expression was a predictive marker of decreased cause-specific survival rate $(\mathrm{P}<0.001)$. Furthermore, low expression of Fer was identified as being an independent marker of decreased cause-specific survival using multivariate analysis (hazard ratio, 7.4; 95\% confidence interval, 1.7-33.0; $\mathrm{P}<0.001)$. The results of the present study suggested that low Fer expression in stromal cells is associated with increased malignant aggressiveness and decreased survival in patients with $\mathrm{RCC}$. $\mathrm{CD} 57^{+} \mathrm{NK}$ cell and $\mathrm{CD} 68^{+}$macrophage regulation in cancer-stromal tissue is considered to affect RCC pathology.
\end{abstract}

Correspondence to: Dr Yasuyoshi Miyata, Department of Urology, Nagasaki University Graduate School of Biomedical Sciences, 1-7-1 Sakamoto, Nagasaki 852-8201, Japan

E-mail: int.doc.miya@m3.dion.ne.jp

Key words: Fer, CD57, CD68, predictive factor, renal cell carcinoma

\section{Introduction}

Renal cell carcinoma (RCC) is a common urological malignancy, and local invasion and metastasis are detected frequently at diagnosis or following radical surgery (1). While radical nephrectomy is typically performed during the organ-confined clinical tumor stages, disease relapse develops in approximately $10 \%$ of patients following surgery (2). In addition, a previous study has demonstrated that the median survival of patients with metastatic RCC is $\sim 13$ months (3). In recent years, various molecular targeting agents have been used in the treatment of patients with advanced RCC (4). The anti-cancer effects of these agents, including prolonged survival, are more effective compared with those of other forms of therapy, such as immunotherapy $(4,5)$. However, the effective period of these molecular targeting therapies is short, and the frequency and severity of adverse reactions are relatively high (5). Thus, further research into the underlying molecular mechanisms of RCC cell invasion and metastasis is required for the development of observational and therapeutic strategies.

The malignant characteristics of RCC are known to be regulated by multiple molecules and signaling pathways. Increased expression of Fps/Fes related (Fer) in cancer cells was previously reported to be associated with high malignant aggressiveness and poor survival in patients with RCC (6). Fer was originally isolated as a tyrosine-protein kinase, which belongs to the subgroup IV of the non-receptor tyrosine-protein kinase family, and is ubiquitously expressed in the cytoplasm and nucleus of a number of mammalian cells (7). Notably, it is well established that Fer is expressed in hematopoietic cells, immune cells and endothelial cells, where it regulates their biological functions (8-10). Fer has been demonstrated to regulate cell proliferation, migration and adhesion, in fibroblasts and various types of immune cells (9,11-13). Conversely, Fer is known to be associated with malignant aggressiveness in several types of cancer, including increased cell proliferation, invasion and metastasis (14-16).

Numerous studies have examined the role of cancer-associated genes, messenger RNAs and proteins in cancer cells, to determine their pathological characteristics, prognostic value and potential for use in targeted therapy $(4,17)$. In recent years, the surrounding cancer-associated stromal cells have also been implicated in tumor development and 
progression (18). While the pathological and prognostic significance of Fer expression in cancer cells has been investigated, the role of Fer expression in RCC tumor-associated stromal cells, including fibroblasts and immune cells, has not been studied thus far. Therefore, the primary aim of the present study is to determine the association between cancer-associated stromal cell Fer expression, and the pathological features, malignant potential and survival rate of patients with RCC. Furthermore, the association between stromal cell Fer expression and cell proliferation, apoptosis, angiogenesis, and macrophage and natural killer (NK) cell density, was investigated in human RCC tissue samples.

\section{Materials and methods}

Patients. Formalin-fixed and paraffin-embedded sections were obtained from surgical specimens from Nagasaki University Hospital (Nagasaki, Japan), between January 1991 and December 2007. Consecutive specimens were used in the present study; however, certain specimens were not analyzed due the low number of cancer cells $(<500)$ resulting from their use in previous investigations $(6,19,20)$. Patients who received neo-adjuvant therapy, including immunotherapy and molecular targeting therapy, were excluded. Tissue samples from 152 patients with RCC, comprising 110 males and 42 females, were analyzed. The mean \pm standard deviation (SD) and median ages at diagnosis were $60.7 \pm 12.2$ and 61 years, respectively. All patients were evaluated using chest X-ray, ultrasonography and computed tomography (CT). In addition, $\mathrm{CT}$ of the lung or brain, and magnetic resonance imaging was performed when metastasis is suspected. Tumors were staged according to the 2002 Tumor-Node-Metastasis Classification of Malignant Tumours (21), and the grade was determined using the criteria set out by Fuhrman et al (22). In the present study, tumors were categorized into the following groups for statistical analysis: Low-[pathological tumor (pT) stages 1 and 2] and high-stage (pT3 and 4), or low-(grades 1 and 2) and high-grade (grades 3 and 4). The present study comprised 129 patients with conventional RCC, 11 with chromophobe RCC and 12 with papillary RCC. The mean \pm SD follow-up period was 43.3 (39.7) months, and 40 patients $(26.3 \%)$ succumbed to disease-specific causes. In addition, 30 wild-type kidney tissue samples obtained from patients with transitional cell carcinoma of the ureter were examined. The present study protocol approved by the ethical standards of the Human Ethics Review Committee of Nagasaki University School of Medicine (Nagasaki, Japan; approval no. 12052899-2). Written informed consent was obtained from all patients prior to enrollment.

Immunohistochemistry. The following antibodies were used in the immunohistochemical staining: Anti-Fer (1:80; no. HPA007641; Sigma-Aldrich; Merck Millipore, Darmstadt, Germany), anti-proliferation marker protein Ki-67 (1:100; no. 7240; Dako, Glostrup, Denmark), anti-cleaved caspase-3 (1:100; no. MAB835; R\&D Systems Europe, Ltd., Abingdon, UK), anti-cluster of differentiation (CD) 31 (1:60: no. NCL-CD31-1A10P; Leica Microsystems, Ltd., Milton Keynes, UK), anti-CD68 (1:100; no. NCL-CD68; Leica Microsystems, Ltd.) and anti-CD57 (1:200; no. MS-136; Lab Vision
Corporation, Fremont, CA, USA). The 5- $\mu$ m-thick sections were stepwise deparaffinized in xylene and rehydrated in graded ethanol solutions. With the exception of the anti-Ki-67 antibody, antigen retrieval was performed at $95^{\circ} \mathrm{C}$ for $40 \mathrm{~min}$. For the anti-Ki-67 antibody, antigen retrieval was performed at $121^{\circ} \mathrm{C}$ for $15 \mathrm{~min}$ in $0.01 \mathrm{M}$ sodium citrate buffer ( $\mathrm{pH} \mathrm{6.0)}$ ). All sections were subsequently immersed in $3 \%$ hydrogen peroxide for $30 \mathrm{~min}$ at room temperature to block endogenous peroxidase activity. The sections were next incubated overnight with the primary antibody at $4{ }^{\circ} \mathrm{C}$ and subsequently washed in $0.05 \%$ Tween-20 in PBS. The sections were then incubated at room temperature with peroxidase, according to the manufacturer's labeled polymer method, using Dako EnVision $+^{\mathrm{TM}}$ Peroxidase (Dako) for $60 \mathrm{~min}$. The peroxidase reaction was visualized using the Pierce DAB Substrate kit (Invitrogen; Thermo Fisher Scientific, Inc., Waltham, MA, USA). The sections were counterstained using hematoxylin, dehydrated stepwise with graded alcohol solutions and washed in xylene, prior to mounting with Poly-Mount ${ }^{\circledR}$ (Polysciences, Inc., Warminster, PA, USA). A number of specimens, previously confirmed to be Ki-67, CD57, CD68 (all tonsil), cleaved caspase-3 (prostate cancer tissue following hormone therapy), and CD31 and Fer (kidney) immunoreactive were used as positive controls. To detect apoptotic cells, in situ apoptotic cell labeling was performed as previously described (23). The ApopTag ${ }^{\circledR}$ In Situ Apoptosis Detection kit (Intergen Company, L.P., Purchase, NY, USA), which is based on the terminal deoxynucleotidyl transferase dUTP nick end labeling (TUNEL) method, was used according to the manufacturer's protocol. As positive control for the TUNEL method, prostate cancer tissue following hormone therapy was used. These prostate specimens were obtained from Nagasaki University Graduate School of Biomedical Sciences (Nagasaki, Japan) and their reliability was confirmed in our previous study (24). Positive and negative control sections were prepared. The negative control consisted of a consecutive section from each sample processed without the primary antibody. Positive and negative controls were set up for each set of experiments.

Evaluation. The expression of all molecules was assessed semi-quantitatively using the percentage of positively stained cancer cells in randomly selected 200 high-power fields (HPFs). Similarly, the densities of positively stained vessels and stromal cells were examined in five HPFs within the tumor area. When the stromal area was small, $\leq 10$ fields were evaluated. In the present study, Fer expression in stromal cells was divided into the following three groups according to the area of positively stained stromal cells: Low $(<25 \%)$, middle (25-50\%) and high (>50\%). Fer expression was evaluated in cancer cells as described previously (3). The proliferative index $(\mathrm{PI})$ represented the percentage of Ki-67-positive cells. The apoptotic index (AI) was estimated using the percentage of TUNEL-positive cells, and was confirmed by the proportion of cleaved caspase-3-positive cells. The microvessel density (MVD) was defined as the number of positively stained vessels $/ \mathrm{mm}^{2}$. The number of positively stained cells $/ \mathrm{mm}^{2}$ defined the densities of CD57- and CD68-stained cells. All slides were examined using an E-400 microscope (Nikon Corporation, Tokyo, Japan). Furthermore, a computer-aided image analysis system (Win ROOF version 5.0; Mitani 

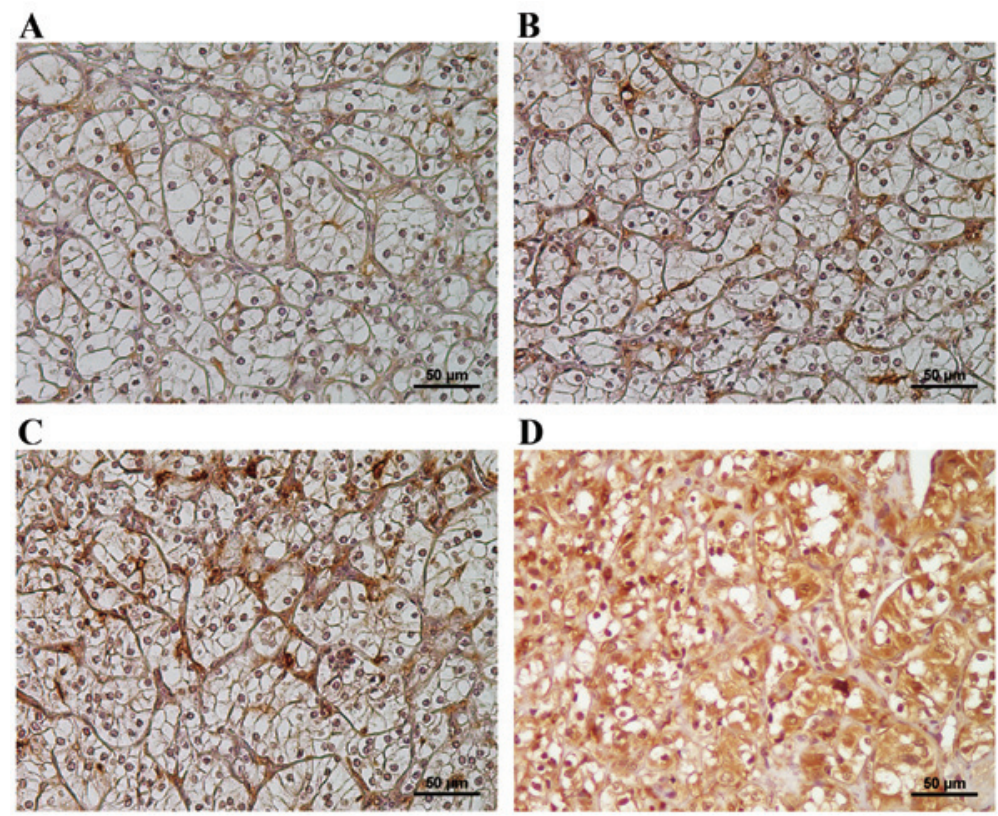

Figure 1. Representative images of (A) low, (B) moderate and (C) high Fer expression in RCC-associated stromal cells. (D) Representative image of high Fer expression in RCC tissue. Magnification, $x 400$. Fer, Fps/Fes related; RCC, renal cell carcinoma.

Corporation, Fukui, Japan) was used to calculate the statistical variables. Each slide was evaluated twice by three independent investigators.

Statistical analysis. Values are expressed as the mean $\pm \mathrm{SD}$. The Student's t-test was used to compare the continuous variables. The $\chi^{2}$ test was used for categorical comparison of the data, while the Scheffé's method was used for multiple comparisons of the data. Survival comparisons were performed using the Kaplan-Meier estimator and the log-rank test. In the survival analysis, a multivariate analysis using the Cox proportional hazards model including all pathological features was conducted. The results are described as the hazard ratio (HR), 95\% confidence interval (CI) and P-value. All statistical analyses were two-sided and were performed using the statistical package StatView for Windows version 5.0 (Abacus Concepts, Berkeley, CA, USA). $\mathrm{P}<0.05$ was considered to indicate a statistically significant difference.

\section{Results}

Fer expression. Representative images of low, middle and high Fer expression in RCC stromal cells are shown in Fig. 1A-C, respectively. Fer-stained immune and fibroblast-like cells were observed in the RCC-associated stromal tissue. A total of 49 (32.2\%), $51(33.6 \%)$ and $52(34.2 \%)$ patients were considered to be in the low, middle and high Fer-expressing groups, respectively. All specimens contained Fer-expressing stromal cells, while conversely, Fer-stained endothelial cells were rare and identification of Fer-stained vessels was difficult. In addition to stromal tissues, Fer expression was detected in the cytoplasm of cancer cells (Fig. 1D). A total of $38 / 49$ patients (74.5\%) in the low stromal Fer-expressing group exhibited high Fer expression in their cancer cells. By contrast, 33/52 patients (63.5\%) exhibited high stromal Fer expression and low cancer cell Fer expression, thus suggesting a significant negative association between Fer expression in stromal tissue and cancer tissue $(\mathrm{P}<0.001)$.

Association between Fer expression and pathological characteristics. As presented in Table I, increased Fer expression in stromal cells was significantly associated with increased Fuhrman grade, pT stage, and lymph node and distal metastasis $(\mathrm{P}<0.001)$. In the present study, a total of 30 patients exhibited metastatic (lymph node and/or distal) RCC tumors. High stromal Fer expression was detected in $1 / 30$ patients (3.3\%) with metastatic RCC (Table I). No significant difference was observed between stromal Fer expression and the RCC pathological subtype $(\mathrm{P}=0.804$; Table I).

Association between Fer expression, malignancy and survival. As shown in Fig. 2, stromal Fer expression was not significantly associated wPI, AI or MVD. As shown in Fig. 3A, increased $\mathrm{CD} 57^{+} \mathrm{NK}$ cell density was significantly associated with high stromal Fer expression group $(\mathrm{P}=0.010$ vs. middle group; $\mathrm{P}<0.001$ vs. low group). By contrast, increased $\mathrm{CD} 68^{+}$macrophage density was significantly associated with the low stromal Fer expression group ( $\mathrm{P}=0.008$ vs. middle group; $\mathrm{P}<0.001$ vs. high group; Fig. $3 \mathrm{~B}$ ). Kaplan-Meier estimators demonstrated that low stromal Fer expression was significantly associated with a decreased cause-specific survival rate $(\mathrm{P}<0.001$; Fig. 4$)$. In addition, univariate Cox proportional hazard models demonstrated that increased grade $(\mathrm{HR}=6.39,95 \% \mathrm{CI}=3.33-12.27, \mathrm{P}<0.001)$, pT stage $(6.54,95 \% \mathrm{CI}=3.40-12.60, \mathrm{P}<0.001)$ and metastasis $(\mathrm{HR}=9.17,95 \% \mathrm{CI}=4.82-17.44, \mathrm{P}<0.001)$ were predictors of decreased cause-specific survival. Following multivariate analysis, the cause-specific survival rate of patients with low stromal Fer expression was significantly decreased compared with patients with high stromal Fer expression 
Table I. Association between stromal Fer expression and pathological characteristics of renal cell carcinoma tissue samples.

\begin{tabular}{|c|c|c|c|c|c|}
\hline \multirow[b]{2}{*}{ Pathological characteristic } & \multirow[b]{2}{*}{ Patients, $\mathrm{n}$} & \multicolumn{3}{|c|}{ Stromal Fer expression } & \multirow[b]{2}{*}{ P-value } \\
\hline & & Low, $\mathrm{n}(\%)(\mathrm{n}=51)$ & Middle, $\mathrm{n}(\%)(\mathrm{n}=52)$ & High, $\mathrm{n}(\%)(\mathrm{n}=49)$ & \\
\hline Pathological type & & & & & 0.804 \\
\hline Conventional & 129 & 43 (33.6) & 45 (35.2) & $40(31.3)$ & \\
\hline Papillary & 12 & $4(30.8)$ & $5(38.5)$ & $4(30.8)$ & \\
\hline Chromophobe & 11 & $4(36.4)$ & $2(18.2)$ & $5(45.5)$ & \\
\hline \multicolumn{6}{|l|}{ pT stage } \\
\hline pT1 & 88 & $13(14.8)$ & 34 (38.6) & $41(46.6)$ & \\
\hline pT2 & 18 & $12(66.7)$ & $4(22.2)$ & $2(11.1)$ & \\
\hline pT3 & 40 & $21(52.5)$ & $14(35.0)$ & $5(12.5)$ & \\
\hline pT4 & 6 & $5(83.3)$ & $0(0.0)$ & $1(16.7)$ & \\
\hline Low (pT1/2) & 106 & $25(23.6)$ & $38(35.8)$ & $14(40.6)$ & $<0.001$ \\
\hline High (pT3/4) & 46 & $26(56.5)$ & $14(30.4)$ & $6(13.0)$ & \\
\hline \multicolumn{6}{|l|}{ LN metastasis } \\
\hline Absence & 137 & $40(29.2)$ & $48(35.0)$ & $49(35.8)$ & 0.001 \\
\hline Presence & 15 & $11(73.3)$ & $4(26.7)$ & $0(0.0)$ & \\
\hline \multicolumn{6}{|l|}{ Distant metastasis } \\
\hline Absence & 126 & $31(24.6)$ & 47 (37.3) & $48(38.1)$ & $<0.001$ \\
\hline Presence & 26 & $20(76.9)$ & $5(19.2)$ & $1(3.8)$ & \\
\hline \multicolumn{6}{|l|}{ Metastasis } \\
\hline Absence & 122 & $29(23.8)$ & $45(36.9)$ & $48(39.3)$ & $<0.001$ \\
\hline Presence & 30 & $22(73.3)$ & $7(23.3)$ & $1(3.3)$ & \\
\hline \multicolumn{6}{|l|}{ Grade } \\
\hline 1 & 57 & $12(21.1)$ & $17(29.8)$ & $28(49.1)$ & \\
\hline 2 & 64 & 17 (26.6) & $29(45.3)$ & $18(28.1)$ & \\
\hline Low $(1 / 2)$ & 121 & $29(24.0)$ & $46(38.0)$ & $46(38.0)$ & $<0.001$ \\
\hline High (3/4) & 31 & $22(71.0)$ & $6(19.4)$ & $3(9.7)$ & \\
\hline
\end{tabular}

Fer, Fps/Fes related; pT, pathological tumor; LN, lymph node.

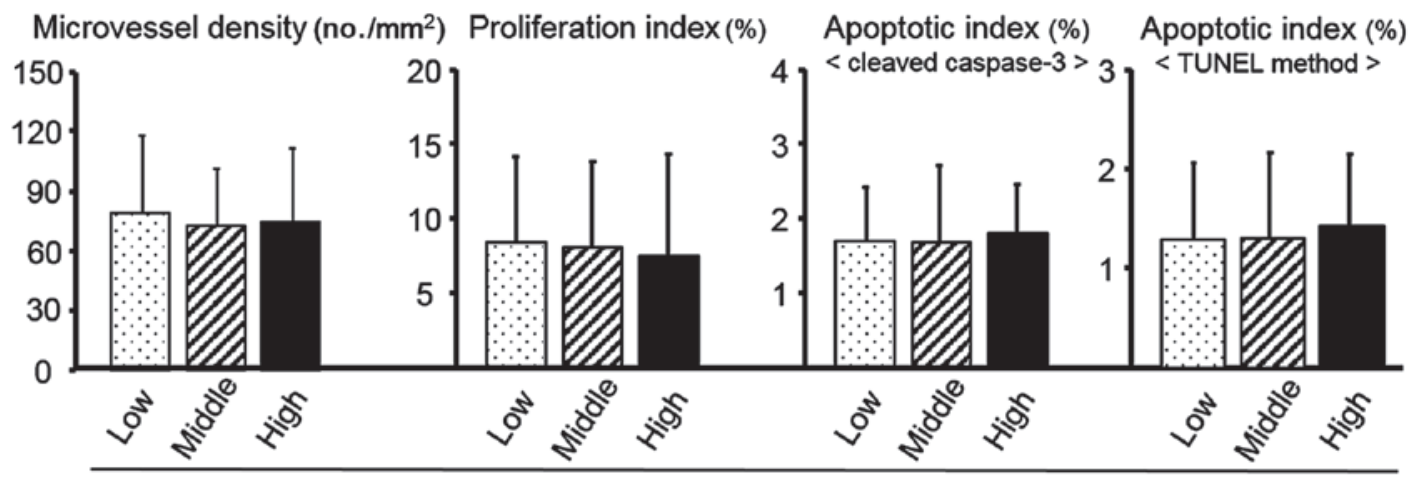

Fer expression in stromal cells

Figure 2. Association between stromal Fer expression and angiogenesis, proliferation, and apoptosis using cleaved caspase-3 antibody staining and the TUNEL assay. No significant associations were observed. Fer, Fps/Fes related; TUNEL, terminal deoxynucleotidyl transferase dUTP nick end labeling.

(HR=7.41; 95\% CI=1.67-33.03; P=0.009; Table II). In addition, moderate stromal Fer expression, high tumor grade and presence of metastasis were identified to be independent predictors of significantly decreased cause-specific survival (Table II).

\section{Discussion}

The results of the present study demonstrated that low Fer expression in stromal cells was associated with an increased pT stage and tumor grade, and the presence of metastasis 
Table II. Association between the pathological characteristics of renal cell carcinoma tissue samples and cause-specific survival.

\begin{tabular}{lccc}
\hline & \multicolumn{3}{c}{ Multivariate analyses } \\
\cline { 2 - 4 } $\begin{array}{l}\text { Pathological } \\
\text { characteristic }\end{array}$ & $\begin{array}{c}\text { Hazard } \\
\text { ratio }\end{array}$ & $\begin{array}{c}\text { 95\% Confidence } \\
\text { interval }\end{array}$ & P-value \\
\hline pT stage & & & \\
Low (pT1/2) & 1.00 & - & - \\
High (pT3/4) & 1.87 & $0.83-4.26$ & 0.133 \\
Metastasis & & & - \\
Absence & 1.00 & - & 0.001 \\
Presence & 3.73 & $1.69-8.22$ & - \\
Grade & & & 0.010 \\
Low (1/2) & 1.00 & - & \\
High (3/4) & 2.70 & $1.27-5.78$ & - \\
Stromal Fer & & & 0.049 \\
expression & & - & 0.009 \\
High & 1.00 & $1.01-20.58$ & \\
Middle & 4.55 & $1.67-33.03$ & \\
Low & 7.41 & & \\
\hline
\end{tabular}

pT, pathological tumor; Fer, Fps/Fes related.

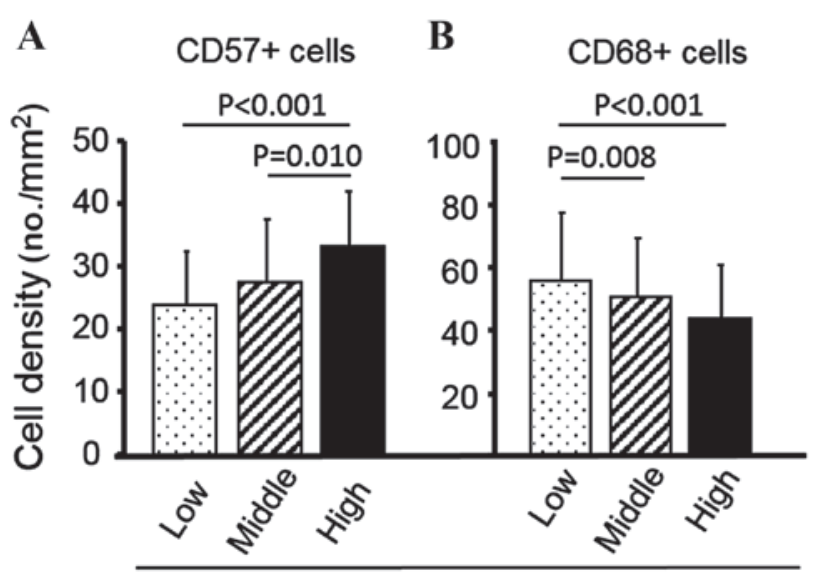

Fer expression in stromal cells

Figure 3. Association between (A) $\mathrm{CD}^{2} 7^{+}$and (B) $\mathrm{CD} 68^{+}$cell density and stromal Fer expression. CD, cluster of differentiation; Fer, Fps/Fes related.

in patients with RCC. Multivariate analysis also identified decreased stromal Fer expression to be indicative of decreased survival. Cancer-associated fibroblasts and infiltrating immune cells within intratumoral areas are known to be important in malignant tumor progression (25). Therefore, an increased understanding of the pathological significance and activity of RCC-associated stromal cells is essential for the development of novel observational and treatment strategies.

Stromal Fer expression in patients with RCC was demonstrated to be inversely associated with Fer expression in cancer cells. Increased Fer expression in RCC cells has previously been demonstrated to be positively associated with

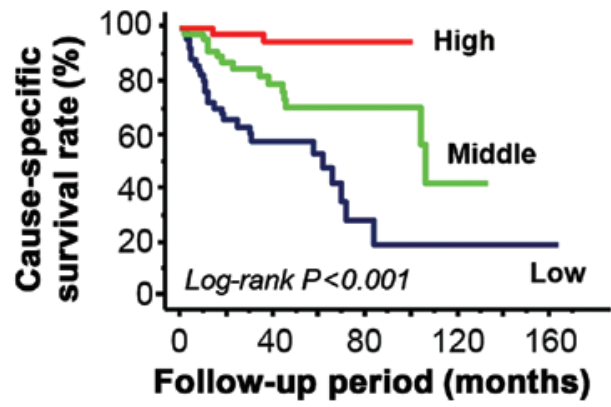

Figure 4. Kaplan-Meier survival curves according to stromal Fer expression status. High expression of stromal Fer was a significant predictor of increased cause-specific survival compared with middle and low expression of stromal Fer (log-rank test, $\mathrm{P}<0.001)$. Fer, Fps/Fes related.

tumor growth and progression in patients with RCC (6). A similar phenomenon has been reported in other malignancies, including breast and lung cancer $(16,26)$. However, the association between stromal Fer expression, tumor malignancy and survival remains to be elucidated.

In the present study, all stromal tissue Fer-positive cells were evaluated collectively, and individual Fer-positive cells were not identified. However, certain Fer-positive cells appeared to be fibroblasts due to their morphological characteristics. In addition, certain Fer-positive cells were considered to be immune cells due to the important role served by the infiltration of immune cells into stromal tissue in RCC. Fibroblasts have been reported to be important in tumor growth, cell invasion and metastasis $(25,27)$. Furthermore, Fer is known to be expressed in fibroblasts, and to be associated with their biological and pathological characteristics $(9,28,29)$. There is, therefore, a possibility that Fer expression in cancer-associated fibroblasts is associated with tumor aggression in various types of cancer, including RCC. The pathological interaction between fibroblasts and tumor cells is regulated by a number of complex mechanisms. For example, wild-type fibroblasts upregulate the secretion of matrix metalloproteinase (MMP)-7 by cervical cancer cells, whereas MMP-2 is produced primarily by cancer-associated fibroblasts (30). Furthermore, cancer-associated fibroblasts affect the migration of glioma cells but not their proliferation (31). Therefore, further investigation into the pathological significance of Fer expression in cancer-associated fibroblast stromal tissue is necessary.

The present study demonstrated that stromal Fer expression was negatively associated with $\mathrm{CD} 68^{+}$cell density. CD68 is frequently used to identify macrophages in human tissue. Increased macrophage density in the tumoral area has been reported to be associated with increased malignant potential and a poor prognosis in multiple types of cancer, including RCC $(31,32)$. Low Fer expression in stromal cells was expected to be associated with decreased aggressiveness and increased survival, due to decreased macrophage density in human RCC tissue. Conversely, stromal Fer expression was negatively associated with intra-tumoral macrophage density. Intra-tumoral $\mathrm{CD} 68^{+}$cell density was considered to reflect the following differences in pathological status: Fer-expressing macrophages do not infiltrate cancer-associated stromal tissue, and/or chemokines and growth factors produced by 
Fer-expressing stromal cells inhibit the growth and migration of macrophages.

Infiltrating macrophages are known to be recruited to sites of disease under various pathological conditions (12). However, the association between Fer expression and immune cell (macrophage) migration in cancer tissues is complex and unclear. Although Fer increases the recruitment and activity of leukocytes and neutrophils in response to various stimuli $(33,34)$, it has also been reported to be an inhibitory factor of neutrophil chemotaxis (35). In addition, it has been reported that Fer expression is associated with the production of vascular endothelial growth factor in myoblast cells (36). However, there is a little information regarding the recruitment of macrophages through Fer-expressing stromal cell-mediated chemokine and growth factor production.

Conversely, $\mathrm{CD} 7^{+}$cell density was positively associated with Fer expression in stromal cells. CD57 is frequently used to detect NK cells in human tissue, which have been recognized to have anti-tumoral properties, including increased survival time, in various malignancies (37-39). This is consistent with the hypothesis that increased stromal Fer expression is associated with decreased malignant potential and improved prognosis in RCC. However, the underlying molecular mechanism of Fer-expressing stromal cell-mediated NK cell recruitment and activation remains to be elucidated. Therefore, further in vitro studies are necessary to understand the biological and pathological role of Fer in NK cell recruitment in RCC.

The results of the present study suggest that Fer expression in cancer-associated stromal tissue serves an anti-oncogenic role in patients with RCC. In a Fer-deficient model, the tumor-free rates in mice targeted with a knock-in Fer-inactivating mutation were increased compared with those of $\mathrm{Fer}^{+/+}$mice (40). Previously, an inhibitor of Fes was identified and used to inhibit the differentiation of osteoclasts (41). Fer and Fes share a high structural homology (8), Therefore, it has been suggested that a subset of Fes inhibitors are likely also to be Fer inhibitors, and may be used in future preclinical cancer models $(41,42)$. However, further investigation into the pathological significance and prognostic value of stromal Fer expression in patients with RCC is required.

In conclusion, the present study demonstrated that stromal Fer expression was negatively associated with aggressiveness in RCC tissue. Additionally, low Fer expression was associated with an improved prognosis in patients with RCC. The increase in $\mathrm{CD} 57^{+} \mathrm{NK}$ cells and the decrease in $\mathrm{CD}_{68}{ }^{+}$macrophages are considered to be regulated by Fer-expressing cancer-associated stromal cells. However, the individual types of Fer-expressing stromal cells could not be identified in the present study. Nevertheless, the results of the present study support the hypothesis that stromal Fer expression in RCC acts as a suppressor of tumor progression. In addition, the present results suggest that combined expression of Fer in stromal and cancer tissue is an effective prognostic biomarker in patients with RCC. Therefore, further studies are required to identify the pathological significance and prognostic value of stromal Fer expression in patients with RCC.

\section{Acknowledgements}

The authors of the present study thank Mr. Takumi Shimogama (Nagasaki University Hospital, Nagasaki, Japan) for his support. The present study was supported by a Grant-in-Aid from the Japan Society for the Promotion of Science (grant no. 25462487). The authors presented the summary of the current manuscript at the 29th Annual European Association of Urology Congress in April 2014 (European Urology Supplements, 13: e195, 2014).

\section{References}

1. Rini BI, Rathmell WK and Godley P: Renal cell carcinoma. Curr Opin Oncol 20: 300-306, 2008.

2. Stephenson AJ, Chetner MP, Rourke K, Gleave ME, Signaevsky M, Palmer B, Kuan J, Brock GB and Tanguay S: Guidelines for the surveillance of localized renal cell carcinoma based on the patterns of relapse after nephrectomy. J Urol 172: 58-62, 2004.

3. Cohen HT and McGovern FJ: Renal-cell carcinoma. New Engl J Med 353: 2477-2490, 2005.

4. Lambea J, Anido U, Etxániz O, Flores L, Montesa Á, Sepúlveda JM and Esteban E: The Wide Experience of the Sequential Therapy for Patients with Metastatic Renal Cell Carcinoma. Curr Oncol Rep 18: 66, 2016.

5. Calvo E, Grünwald V and Bellmunt J: Controversies in renal cell carcinoma: Treatment choice after progression on vascular endothelial growth factor-targeted therapy. Eur J Cancer 50: 1321-1329, 2014.

6. Miyata Y, Kanda S, Sakai H and Greer PA: Feline sarcoma-related protein expression correlates with malignant aggressiveness and poor prognosis in renal cell carcinoma. Cancer Sci 104: 681-686, 2013.

7. Ben-Dor I,Bern O,Tennenbaum T and Nir U: Cell cycle-dependent nuclear accumulation of the p94fer tyrosine kinase is regulated by its $\mathrm{NH} 2$ terminus and is affected by kinase domain integrity an. Cell Growth Differ 10: 113-129, 1999.

8. Greer P: Closing in on the biological functions of FPS/FES and FER. Nat Rev Mol Cell Biol 3: 278-289, 2002.

9. Sangrar W, Gao Y, Scott M, Truesdell P and Greer PA: Fer-mediated cortactin phosphorylation is associated with efficient fibroblast migration and is dependent on reactive oxygen species generation during integrin-mediated cell adhesion. Mol Cell Biol 27: 6140-6152, 2007.

10. Craig AW: FES/FER kinase signaling in hematopoietic cells and leukemias. Front Biosci (Landmark Ed) 17: 861-875, 2012.

11. Kim L and Wong TW: Growth factor-dependent phosphorylation of the actin-binding protein cortactin is mediated by the cytoplasmic tyrosine kinase FER. J Biol Chem 273: 23542-23548, 1998.

12. Hayun R, Shpungin S, Malovani H, Albeck M, Okun E, Nir U and Sredni B: Novel involvement of the immunomodulator AS101 in IL-10 signaling, via the tyrosine kinase Fer. Ann N Y Acad Sci 1095: 240-250, 2007.

13. Yoneyama T, Angata K, Bao X, Courtneidge S, Chanda SK and Fukuda M: Fer kinase regulates cell migration though $\alpha$-dystroglycan glycosylation. Mol Biol Cell 23: 771-780, 2012.

14. Allard P, Zoubeidi A, Nguyen LT, Tessier S, Tanguay S, Chevrette M, Aprikian A and Chevalier S: Links between Fer tyrosine kinase expression levels and prostate cell proliferation. Mol Cell Endocrinol 159: 63-77, 2000.

15. Li H, Ren Z, Kang X, Zhang L, Li X, Wang Y, Xue T, Shen Y and Liu Y: Identification of tyrosine-phosphorylated proteins associated with metastasis and functional analysis of FER in human hepatocellular carcinoma cells. BMC Cancer 9: 366, 2009.

16. Ivanova IA, Vermeulen JF, Ercan C, Houthuijzen JM, Saig FA, Vlug EJ, van der Wall E, van Diest PJ, Vooijs M and Derksen PW: FER kinase promotes breast cancer metastasis by regulating $\alpha 6$ - and $\beta 1$-integrin-dependent cell adhesion and anoikis resitance. Oncogene 32: 5582-5592, 2013.

17. Vitale MG and Cartenì G: Clinical management of metastatic kidney cancer: The role of new molecular drugs. Future Oncol 12: 83-93, 2016. 
18. Hashimoto O, Yoshida M, Koma Y, Yanai T, Hasegawa D, Kosaka Y, Nishimura N and Yokozaki H: Collaboration of cancer-associated fibroblasts and tumour-associated macrophages for neuroblastoma development. J Pathol 240: 211-223, 2016.

19. Watanabe S, Miyata Y, Matsuo T, Mochizuki Y, Nishikido M, Hayashi T and Sakai H: High density of tryptase-positive mast cells in patients with renal cell carcinoma on hemodialysis: Correlation with expression of stem cell factor and protease activated receptor-2. Hum Pathol 43: 888-897, 2012.

20. Matsuo T, Miyata Y, Watanabe S, Ohba K, Hayashi T, Kanda S and Sakai H: Pathologic significance and prognostic value of phosphorylated cortactin expression in patients with sarcomatoid renal cell carcinoma. Urology 476. e9-15, 2011.

21. Greene FL, Page DL, Fleming ID, Fritz AG, Balch CM, Haller DG and Morrow M (eds): AJCC Cancer Staging Manual 6th edition. Springer-Verlag, New York, NY, pp157-164, 2002.

22. Fuhrman SA, Lasky LC and Limas C: Prognostic significance of morphologic parameters in renal cell carcinoma. Am J Surg Pathol 6: 655-663, 1982.

23. Miyata Y, Watanabe S, Kanetake H and Sakai H: Thrombospondin-1-derived $4 \mathrm{~N} 1 \mathrm{~K}$ peptide expression is negatively associated with malignant aggressiveness and prognosis in urothelial carcinoma of the upper urinary tract. BMC Cancer 12: 372, 2012.

24. Watanabe S, Miyata Y, Kanda S, Iwata T, Hayashi T, Kanetake $H$ and Sakai H: Expression of X-linked inhibitor of apoptosis protein in human prostate cancer specimens with and without neo-adjuvant hormonal therapy. J Cancer Res Clin Oncol 136 : 787-793, 2010

25. De Wever O, Demetter P, Mareel M and Bracke M: Stromal myofibroblasts are drivers of invasive cancer growth. Int J Cancer 123: 2229-2238, 2008.

26. Ahn J, Truesdell P, Meens J, Kadish C, Yang X, Boag AH and Craig AW: Fer protein-tyrosine kinase promotes lung adenocarcinoma cell invasion and tumor metastasis. Mol Cancer Res 11: 952-963, 2013

27. Kalluri R and Zeisberg M: Fibroblasts in cancer. Nat Rev Cancer 6: 392-401, 2006.

28. Kim L and Wong TW: The cytoplasmic tyrosine kinase FER is associated with the catenin-like substrate pp120 and is activated by growth factors. Mol Cell Biol 15: 4553-4561, 1995.

29. Rosato R, Veltmaat JM, Groffen J and Heisterkamp N Involvement of the tyrosine kinease fer in cell adhesion. Mol Cell Biol 18: 5762-5770, 1998.

30. Fullár A, Dudás J, Oláh L, Hollósi P, Papp Z, Sobel G, Karászi K, Paku S, Baghy K and Kovalszky I: Remodeling of extracellular matrix by normal and tumor-associated fibroblasts promotes cervical cancer progression. BMC Cancer 15: 256, 2015.
31. Trylcova J, Busek P, Smetana K Jr, Balaziova E, Dvorankova B, Mifkova A and Sedo A: Effect of cancer-associated fibroblasts on the migration of glioma cells in vitro. Tumour Biol 36: 5873-5879, 2015

32. Ohba K, Miyata Y, Kanda S, Koga S, Hayashi T and Kanetake H: Expression of urokinase-type plasminogen activator, urokinase-type plasminogen activator receptor and plasminogen activator inhibitors in patients with renal cell carcinoma: Correlation with tumor associated macrophage and prognosis. J Urol 174: 461-465, 2005.

33. Tchou J, Zhang PJ, Bi Y, Satija C, Marjumdar R, Stephen TL, Lo A, Chen H, Mies C, June CH. et al: Fibroblast activation protein expression by stromal cells and tumor-associated macrophages in human breast cancer. Hum Pathol 44: 2549-2557, 2013.

34. McCafferty DM, Craig AW, Senis YA and Greer PA: Absence of Fer protein-tyrosine kinase exacerbates leukocyte recruitment in response to endotoxin. J Immunol 168: 4930-4935, 2002.

35. Khajah M, Andronegui G, Chan R, Craig AW, Greer PA and McCafferty DM: Fer kinase limits neutrophil chemotaxis toward end target chemoattractants. J immunol 190: 2208-2216, 2013.

36. Salem Y, Shpungin S, Pasder O, Pomp O, Taler M, Malovani H and Nir U: Fer kinase sustains the activation level of ERK1/2 and increases the production of VEGF in hypoxic cells. Cell Signal 17: 341-353, 2005.

37. Donskov $\mathrm{Fa}$ and von der Maase $\mathrm{H}$ : Impact of immune parameters on long-term survival in metastatic renal cell carcinoma. J Clin Oncol 24: 1997-2005, 2006.

38. Vandercappellen J, Van Dammet J and Struyf S: The role of CXC chemokines and their receptors in cancer. Cancer Lett 267: 226-244, 2008.

39. Mueller SK, Altvater B, Chen C, Kailayangiri S, Ahlmann M, Dirksen U, Juergens H and Rossig C: Zoledronic acid negatively affects the expansion of in vitro activated human NK cells and their cytolytic interactions with Ewing sarcoma cells. Oncol Rep 29: 2348-2354, 2013.

40. Sangrer W, Shi C, Mullins G, LeBrun D, Ingalls B and Greer PA: Amplified Ras-MARK signal states correlate with accelerated EGFR internalization, cytostasis and delayed HER2 tumor onset in Fer-deficient model systems. Oncogene 34: 4109-4117, 2015.

41. Hellwig S, Miduturu CV, Kanda S, Zhang J, Filippakopoulos P, Salah E, Deng X, Choi HG, Zhou W, Hur W, et al: Small-molecule inhibitors of the c-Fes protein-kinase kinase. Chem Biol 19: 529-540, 2012.

42. Kanda S and Miyata Y: The c-Fes protein tyrosine kinase as a potential anti-angiogenic target in cancer. Front Biosci (Landmark Ed) 16: 1024-1035, 2011. 